\title{
Mitral valve replacement in patients with severely calcified mitral valve annulus: Surgical technique
}

Tomislav Mihaljevic, MD, ${ }^{\mathrm{a}}$ Marijan Koprivanac, MD, ${ }^{\mathrm{a}}$ Marta Kelava, MD, ${ }^{\mathrm{a}}$ Nicholas G. Smedira, MD, ${ }^{\mathrm{a}}$ Bruce W. Lytle, MD, ${ }^{a}$ and Eugene H. Blackstone, MD, ${ }^{\mathrm{a}, \mathrm{b}}$ Cleveland, Ohio, and Abu Dhabi, United Arab Emirates

Mitral annular calcification, a degenerative process affecting mostly elderly patients, is a formidable surgical challenge. Adoption of aggressive débridement is limited by

From the Department of Thoracic and Cardiovascular Surgery, ${ }^{\mathrm{a}}$ Heart and Vascular Institute, Cleveland Clinic, Cleveland, Ohio, and Abu Dhabi, United Arab Emirates; and the Department of Quantitative Health Sciences, ${ }^{\text {b }}$ Research Institute, Cleveland Clinic, Cleveland, Ohio.

Received for publication Sept 11, 2012; revisions received Feb 6, 2013; accepted for publication Feb 13, 2013; available ahead of print April 8, 2013.

Address for reprints: Tomislav Mihaljevic, MD, Heart and Vascular Institute,

Cleveland Clinic Abu Dhabi, Baniyas Towers, 11th Floor, Abu Dhabi, United

Arab Emirates (E-mail: mihaljt@ccf.org).

J Thorac Cardiovasc Surg 2013;146:233-5

$0022-5223 / \$ 36.00$

Copyright (c) 2013 by The American Association for Thoracic Surgery

http://dx.doi.org/10.1016/j.jtcvs.2013.02.034

risk of atrioventricular groove disruption and the technical complexity of pericardial patch reconstruction of the débrided area. The most challenging part of the operation is to place the patch adequately into a difficult-tovisualize, small, hypertrophied ventricular cavity in severe mitral stenosis. We provide a step-by-step description of a reproducible technique that is based on David and colleagues' patch procedure. ${ }^{1}$

\section{SURGICAL TECHNIQUE}

After sternotomy and establishment of cardiopulmonary bypass, the mitral valve is exposed through a left atriotomy and inspected to ascertain extent of calcification. Commonly, there is horseshoe calcification of the posterior mitral annulus extending from trigone to trigone, often into the base of the posterior leaflet (Figure 1). It is frequently accompanied by a variable degree, usually small, of anterior annular calcification (Video 1).

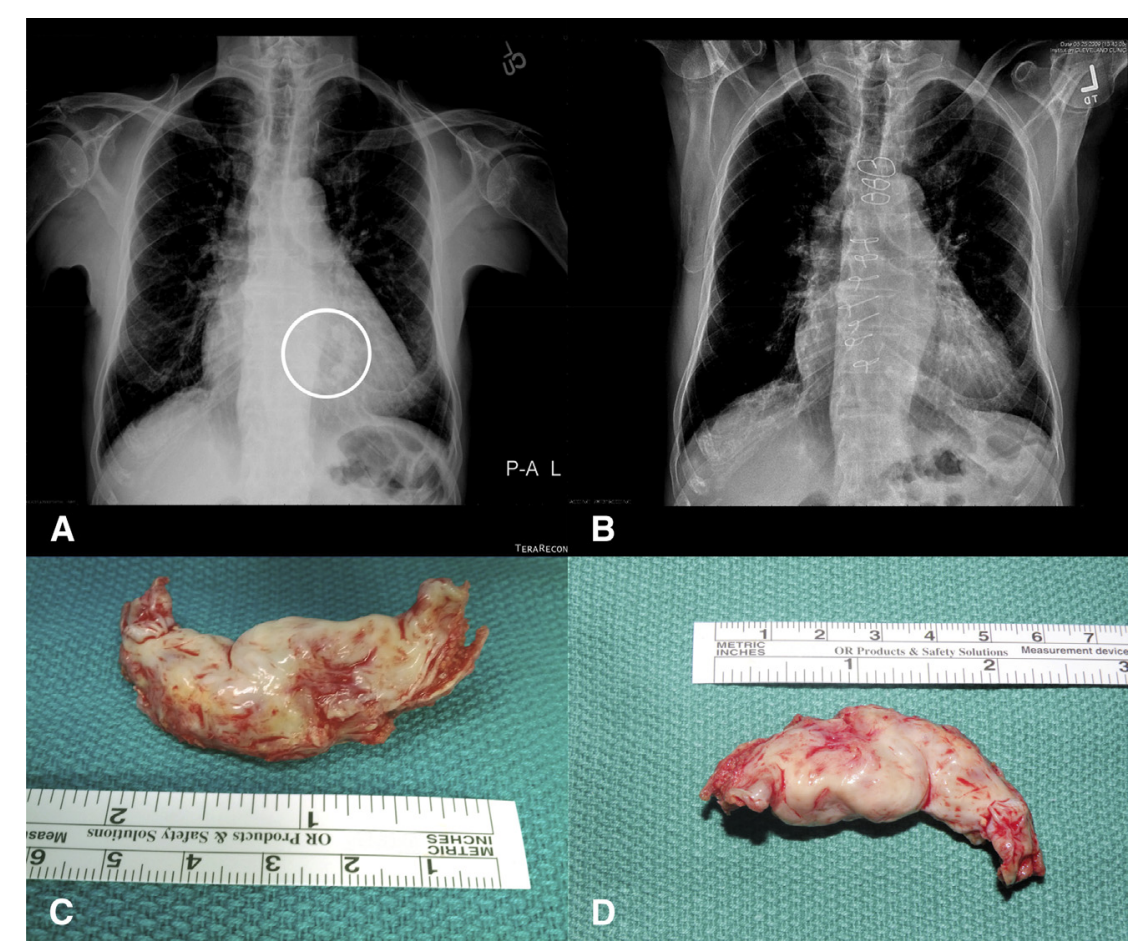

FIGURE 1. Mitral annular calcification before and after decalcification. A, Preoperative chest radiograph with visible mitral annular calcification (circle). B, Postoperative chest radiograph. C and D, En bloc excised mitral annulus with posterior leaflet. 

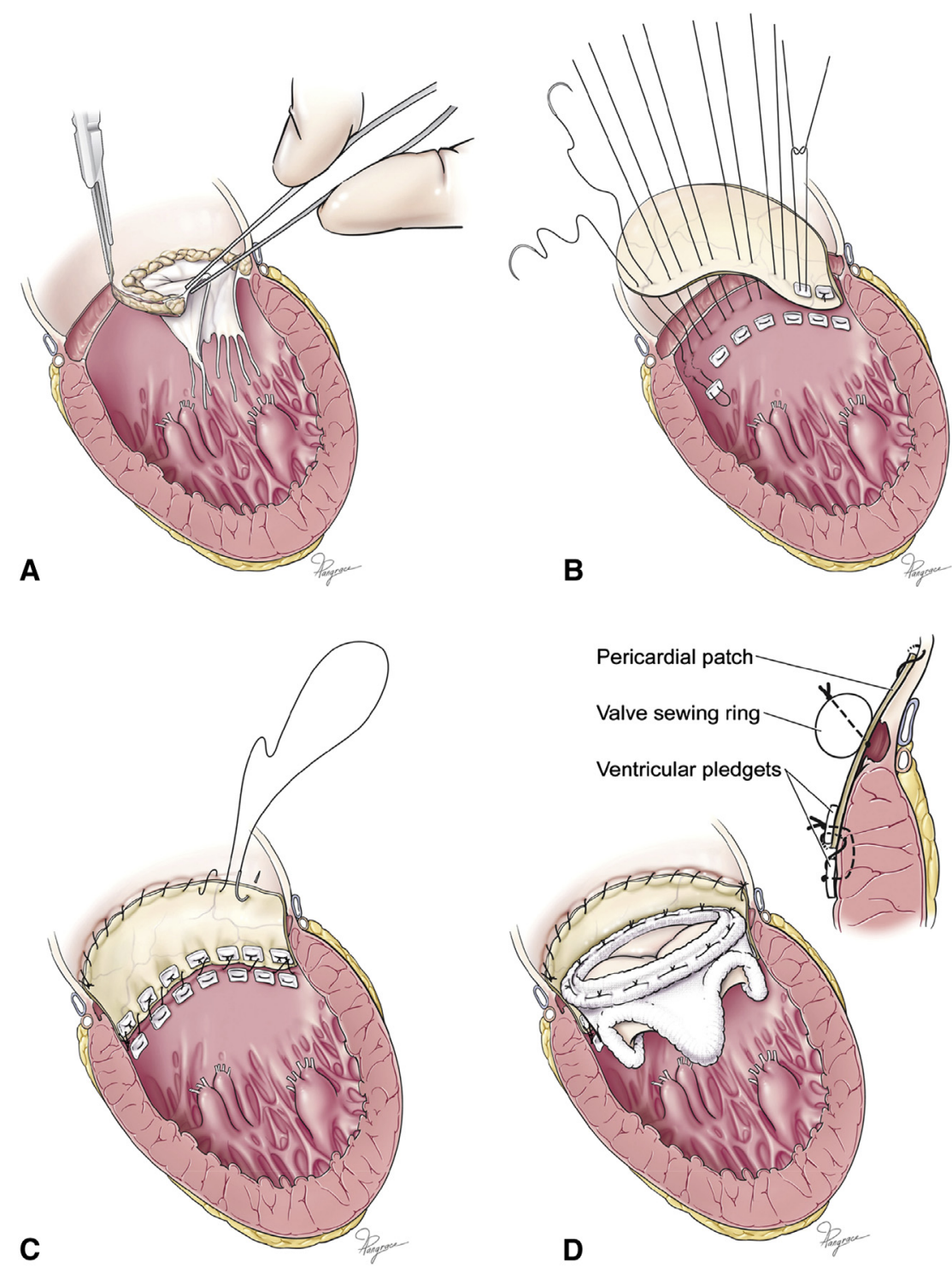

FIGURE 2. Surgical technique. A, Sharp en bloc decalcification. B, Patch parachuting. C, Patch attachment. D, Completed procedure.

The horseshoe calcification is excised en bloc with the posterior leaflet (Figures 1 and 2, A) with a No. 15 blade that is exchanged often to maintain sharp, controlled dissection. One-piece removal of calcified annulus and leaflet expedites surgery, avoids calcium dispersion, and lowers risk of atrioventricular groove disruption and damage to the circumflex coronary artery. Residual calcification is débrided by roungers.

A 2- to 3-cm wide autologous pericardial patch is harvested, with the length varying with the extent of débridement. With No. 4-0 polypropylene sutures and pledgets, stitches are placed through the inner surface of the left ventricular wall with both needles, so that the pledget lies on the ventricular wall. These sutures must be placed deep into the ventricle beyond the area of débridement to the preserved endocardium. The needles are then passed through the patch. After 6 to 8 sutures, the patch is parachuted into the ventricle beyond the point of débridement (Figure 2, $B$ ), covering the entire débrided area between trigones. This suture line is reinforced with a running suture placed through the line of pledgets and patch. Deploying the patch this way overcomes the challenge of visualization, is easier than a running suture technique, provides less tension on individual sutures, and reduces risk of patch tearing. On the atrial side, a running suture is used for patch attachment; this simpler technique can be used because tension on the patch and risk of tearing are low (Figure 2, C).

If the anterior leaflet is preserved (chordal-sparing technique), it is mobilized, divided at midline, and fixed to the lateral and medial aspects of the annulus. A valve prosthesis is then attached into the reconstructed annulus (Figure 2,D). The left atrium is closed and the procedure concluded in standard fashion. 


\section{RESULTS}

From 2006 to 2012, this technique was used in 15 patients, mean age 72 years, $67 \%$ female. There were no strokes, but there were 3 in-hospital deaths, none directly related to the operative technique. One patient died on postoperative day 2 of mesenteric ischemia, another on postoperative day 24 of multisystem organ failure, and the third on postoperative day 72 of severe respiratory failure.

\section{DISCUSSION}

Two groups of techniques have been described for addressing severe mitral annular calcification. The first avoids decalcification. ${ }^{2-4}$ It includes prosthesis placement-intraatrial, semi-intra-atrial, or intra-annular-after drilling holes or plicating atrial tissue and placing the prosthesis into a new annulus constructed from mitral leaflets and atrial wall. Disadvantages of intra-atrial techniques include transferring high ventricular pressure into the atrium, increasing risk of dehiscence, hemorrhage, and aneurysm formation and rupture.

Disadvantages of intra-annular techniques are the risks of paravalvar leak, valve dehiscence, and embolism from the friable calcified annulus. In addition, ability to pass sutures through the annulus depends on amount of noncalcified fibrous tissue, making these techniques less reproducible. A similar problem is encountered when placing sutures into degenerated and fragile leaflets. Consequently, this technique mandates a smaller prosthesis, which can result in prosthesis-patient mismatch.
Although intra-atrial and intra-annular techniques have been advocated as simpler alternatives to decalcification and patching, attempts to reduce risk by forming a new annulus, adding collars, plicating atrial tissue over the prostheses, and other solutions increase complexity. The quality and durability of these techniques are unknown.

The second group of $^{2,3,5}$ of techniques is characterized by excision of the calcified annulus and annular reconstruction, usually with a pericardial patch. ${ }^{1}$ The greatest concerns are that extensive débridement increases risk of atrioventricular disruption, circumflex coronary artery injury, and ventricular rupture; however, the patch increases integrity of the atrioventricular groove, lowering risk of potentially fatal complications. Nevertheless, its perceived technical complexity has limited its adoption. We find the surgical technique described to be simple, reproducible, and safe, allowing valve replacement even in patients with severe mitral annular calcification.

\section{References}

1. David TE, Feindel CM, Armstrong S, Sun Z. Reconstruction of the mitral anulus. A ten-year experience. J Thorac Cardiovasc Surg. 1995;110:1323-32.

2. Smedira NG. Mitral valve replacement with a calcified annulus. Operative Tech Thorac Cardiovasc Surg. 2003;8:2-13.

3. Mills NL, McIntosh CL, Mills LJ. Techniques for management of the calcified mitral annulus. J Card Surg. 1986;1:347-55.

4. Nataf P, Pavie A, Jault F, Bors V, Cabrol C, Gandjbakhch I. Intraatrial insertion of a mitral prosthesis in a destroyed or calcified mitral annulus. Ann Thorac Surg. 1994;58:163-7.

5. Casselman FP, Gillinov AM, McDonald ML, Cosgrove DM 3rd. Use of the anterior mitral leaflet to reinforce the posterior mitral annulus after debridement of calcium. Ann Thorac Surg. 1999;68:261-2.

\title{
Successful surgical treatment of aortoesophageal fistula after emergency thoracic endovascular aortic repair: Aggressive débridement including esophageal resection and extended aortic replacement
}

\author{
Hiroshi Munakata, MD, PhD, Katsuhiro Yamanaka, MD, Kenji Okada, MD, PhD, and Yutaka Okita, MD, PhD, \\ Kobe, Japan
}

\footnotetext{
From the Division of Cardiovascular Surgery, Department of Surgery, Kobe University Graduate School of Medicine, Kobe, Japan.

Disclosures: Authors have nothing to disclose with regard to commercial support.

Received for publication Jan 25, 2013; accepted for publication Feb 27, 2013; available ahead of print March 25, 2013.

Address for reprints: Hiroshi Munakata MD, PhD, Division of Cardiovascular Surgery, Department of Surgery, Kobe University Graduate School of Medicine, 7-5-2, Kusunoki-cho, Chuo-ku, Kobe, 650-0017 (E-mail: h-munakata@k7.dion. ne.jp).

J Thorac Cardiovasc Surg 2013;146:235-7

$0022-5223 / \$ 36.00$

Copyright (c) 2013 by The American Association for Thoracic Surgery

http://dx.doi.org/10.1016/j.jtcvs.2013.02.064
}

In recent years, thoracic endovascular aortic repair (TEVAR) has emerged as a promising, less-invasive alternative to open surgery in the treatment of aortic aneurysms and dissections ${ }^{1}$; however, some catastrophic complications do occur after TEVAR. Aortoesophageal fistula (AEF) is very rare but is associated with high mortality and morbidity. ${ }^{2}$

Here we report the successful surgical treatment of a seriously infected AEF after TEVAR. Aggressive débridement, which included the infected aortic wall, endovascular stentgrafts, and esophagus, was followed by replacement of the 